\title{
Developing and Testing a Theoretical Framework for Computer-Mediated Transparency of Local Governments
}

Stephan G. Grimmelikhuijsen is a postdoctoral researcher in the Utrecht School of Governance, Utrecht University. His research interests include citizen trust in government, electronic government, and transparency.

E-mail: s.g.grimmelikhuijsen@uu.n|

Eric W. Welch is associate professor in the Department of Public Administration and director of the Science, Technology and Environment Policy Lab at the University of Illinois at Chicago. His research interests include electronic government, science and technology policy, and environment policy. E-mail: ewwelch@uic.edu

Public Administration Review Vol. 72, Iss. 4, pp. 562-571. (C 2012 by The American Society for Public Administration. DOI: 10.111/j.1540-6210.2012.02532.x.

This article contributes to the emerging literature on transparency by developing and empirically testing a theoretical framework that explains the determinants of local government Web site transparency. It aims to answer the following central question: What institutional factors determine the different dimensions of government transparency? The framework distinguishes three dimensions of transparency — decision making transparency, policy information transparency, and policy outcome transparency — and hypothesizes three explanations for each: organizational capacity, political infuence, and group influence on government. Results indicate that each dimension of transparency is associated with different factors. Decision-making transparency is associated with political influence; when left-wing parties are strong in the local council, local government tends to be more transparent. Policy information transparency is associated with media attention and external group pressure, and policy outcome transparency is associated with both external group pressure and the organizational capacity. The authors discuss the implications for policy and administration.

$\mathrm{T}$ ransparency is considered by public administration scholars and practitioners to be a quintessential democratic value that undergirds a trustworthy, highperforming, and accountable government (Hood 2006; Kjaer 2004). Citizens, officials, and researchers recognize that when government processes and outcomes are not transparent, the foundation for accountability is

This article develops and
empirically tests a theoretical
framework to explain the
institutional determinants
of transparency.
weakened (Bovens 2007). Policy makers and scholars see transparency as an enabler of "good governance" (Hood 2006) because it likely encourages better performance and reduces corruption (Meijer 2009). In practice, numerous national-level governments have enacted freedom of information laws ${ }^{1}$ to guide the appropriate provision of information (see Relly and Sabharwal 2009). Hence, there is benefit to gaining a better understanding of the concept, its determinants, and the consequences of transparency.

Nevertheless, the transparency literature is fragmented and still underdeveloped. Prior work has noted that the field of public administration lacks a theoretical framework to adequately account for variation in the types of transparency and the contexts in which transparency is applied (Meijer 2009). The topic of transparency is often addressed within the e-government literature; however, the multidimensional nature of the construct is generally not investigated (Layne and Lee 2001; Tolbert and Mossberger 2006; Wong and Welch 2004). Additionally, prior empirical studies have ignored transparency at the local government level, focusing on explaining variation in transparency statistics either across countries or across state governments in the United States (e.g., Pina, Torres, and Royo 2007; Relly and Sabharwal 2009; Welch and Wong 2001; World Bank 1998). This article recognizes these limitations and seeks to integrate and build on existing transparency research and apply it to the local government context.

To begin, this article develops and empirically tests a theoretical framework to explain the institutional determinants of transparency. We distinguish between transparency of decision-making processes, transparency of policy content information, and transparency of policy outcomes. The framework hypothesizes that three factors - organizational capacity, political influence, and group influence-predict transparency outcomes. The organizational capacity perspective envisions transparency as part of enhanced electronic service delivery; the political perspective builds on the premise that information disclosure is never entirely neutral because it represent political interests; and group influence recognizes that external entities (media, industry, citizens, and environmental groups) create 
pressure on local governments for greater transparency. In general, the article addresses the question, what institutional factors determine different dimensions of local government Web site transparency?

The article tests the framework using e-government, institutional, and organizational data collected from 80 Dutch municipalities and their local environmental agencies. Regression analysis is used to model how different institutional factors are associated with different types of transparency, as measured by local environmental agency Web sites.

\section{Framework for Analysis of Computer-Mediated Transparency}

\section{Definition and Determinants of Government Transparency}

Because a primary goal of this article is to build a framework for analysis of transparency, it is first necessary to define the term. Most definitions recognize that transparency relates to an entity's revelation of information about its own decision processes, procedures, functioning, and performance (Curtin and Meijer 2006; Gerring and Thacker 2004; Welch and Wong 2001). As such, transparency typically incorporates multiple components, including inward observability, active disclosure, and external assessability. Inward observability refers to the ability of individuals and groups outside the organization to monitor activities and decisions undertaken within the organization. Active disclosure concerns the extent to which an organization disseminates information about its activities and their outcomes. External assessability refers to the inclination of the organization toward evaluation and critique by external groups and individuals. Hence, transparency is defined as the disclosure of information by an organization that enables external actors to monitor and assess its internal workings and performance. ${ }^{2}$ This is a broad definition that encompasses both "active" disclosure activity undertaken proactively by the agency and "passive" forms of transparency in which the agency responds reactively to external demands (e.g., through freedom of information requests).

Prior research has shown that transparency occurs as a part of separate events and processes of government. Heald (2006) identifies different points at which government determines the level of transparency: (1) transparency of decision-making processes, (2) transparency of policy content, and (3) transparency of policy outcomes or effects. As government makes decisions about policy, it engages in a search process in which problems are presented, potential solutions are identified, and choices are made given the constraints and opportunities that exist at that point in time. Decision-making transparency concerns the degree of openness about the steps taken to reach a decision and the rationale behind the decision. Decisionmaking transparency has been more extensively conceptualized and operationalized by Drew and Nyerges (2004). Policy content transparency refers to the information disclosed by government about policies: what the adopted measures are, how they are supposed to solve a problem, how they will be implemented, and what implications they will have for citizens and other affected groups. Finally, policy outcome transparency captures the provision and timeliness of information about the effects of policies. This event and process model for transparency is presented in figure 1 .

Levels of transparency within a single local government may not be equivalent across events and processes. For example, a municipal

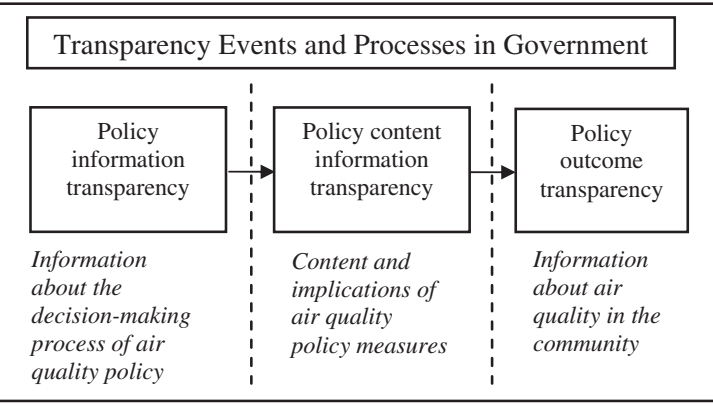

Source: Adapted from Heald (2006).

\section{Figure 1 Event and Process Model}

government may be much more willing to provide information about the content and implications of a completed policy than to present information about the decision-making process. Similarly, the factors that determine levels of transparency may differ depending on the process or event. For example, local governments that have relatively low technical capacity may be more able to provide policy content information than policy outcome information, which may require substantial data collection and analysis skills.

The separation of processes and events provides one element of the framework for analysis of transparency. The second element concerns the specific factors that may predict transparency outcomes. Our discussion of the determinants takes place within the context of computer-mediated transparency, which has recently received new attention in the literature (Meijer 2009; Piotrowski and Borry 2009) and promises to provide insight into government transparency in general.

\section{Computer-Mediated Transparency for Environmental Policy in Dutch Local Government}

Information and communication technologies, and the Internet in particular, hold the potential to greatly facilitate the provision of government information to the public because information can be disclosed at relatively low cost, without the traditional boundaries of space and time (Curtin and Meijer 2006; Welch, Hinnant, and Moon 2005). Such information can be read by almost anyone with access to the Internet, independent of time or place. Although the digital divide literature shows that there are inequalities in access to and use of the Internet in society (Mossberger, Tolbert, and McNeal 2007), the Internet revolution has created an information culture in which most citizens have and expect access to a great deal of online information (Shapiro 1999).

Traditionally, scholars interested in measuring computer-mediated transparency have focused on the transparency content of Web sites. For example, the Cyberspace Policy Research Group developed a Website Attribute Evaluation System that has been widely used (in adapted form) by others such as West (2001) and, more recently, Pina, Torres, and Royo (2007). These authors have sought to capture transparency content in terms of the online availability and organization of reports or laws. While technical accessibility is easily measured, it nevertheless represents only one part of content transparency. Focusing on another type of transparency, Drew and Nyerges (2004) developed operationalizable criteria to assess seven objectives of government decision-making transparency: clarity, 
accessibility, integration, logic/rationale, truth/accuracy, openness, and accountability. Finally, taking a demand-side approach, Tolbert and Mossberger (2006) operationalize transparency from the perspective of end users by asking them, "Are you able to get the information and online services you are seeking online?" This shift of focus to the user's perspective is valuable but also neglects the multiple dimensions of transparency and their subtleties. In general, these prior efforts to measure transparency have not examined the full range of transparency events and processes.

Environmental policy and air pollution programs in particular are closely linked with government transparency. Air pollution is a widespread problem in numerous cities in a great deal of countries worldwide (see, e.g., a report on the main environmental problems in the OECD countries; OECD 2008). In the Netherlands, all local governments must comply with the Dutch Freedom of Information Act and the Aarhus Treaty. The Aarhus Treaty was adopted on June 25, 1998, and entered into force on October 30, 2001, by the United Nations Economic Commission for Europe.

The Dutch Freedom of Information Act prescribes that environmental information should be disclosed more generously than other information. The Aarhus Treaty has been ratified by the Netherlands and 40 other primarily European and Central Asian countries. All ratifying countries commit to implementing easier (electronic) means of public access to environmental information, which extends to governments at the local level. This article examines the case of air pollution in local governments because of its importance in public policy. Further, as indicated by the existence of these national and supranational regulations, information disclosure is an important issue in air pollution policy. Hence, air pollution is considered to be a highly relevant case for studying transparency.

The topic of air quality in cities receives a considerable amount of media coverage worldwide. Air quality in Beijing, for instance, was a major issue prior to the Olympic Games of 2008 held in China. More generally, the media report on municipalities that are not meeting the standards or the dangers of bad air quality.

Furthermore, governments in Europe are obliged to meet European Union (EU) directives $^{3}$ about air quality. Local governments in the Netherlands are required to set up a policy plan with measures to combat air pollution if the air is found to be polluted. Municipalities have to report on several air pollutants, including nitrogen dioxide, fine dust particles, benzene, and carbon monoxide. The EU standards are widely exceeded in the Netherlands. Many informed Dutch citizens are aware of this, and because of the well-recognized risks of bad air quality, there exists a strong demand for information about local air quality. As a result, air pollution and transparency about it have become politically salient local policy issues.

\section{Determinants of Transparency of Government}

There is high potential for local government transparency. Local governments have large quantities of information stored in their internal systems, and, to a certain extent, they are free to choose which internal information is disclosed to the public. Nevertheless, it is anticipated that local governments vary substantially in their transparency levels. Because transparency choices made by governments are visible on the Internet, it is relevant to ask what determines transparency. The following discussion develops three different rationales to explain why some governments are more transparent than others. These three rationales-organizational, political, and group influence-are presented in turn.

\section{A Government Capacity Perspective on Transparency}

The e-government literature has focused heavily on the improvement of efficiency and electronic service delivery to citizens (e.g., Layne and Lee 2001; Moon 2002). E-government is said to cause a shift in the traditional bureaucratic paradigm by making government more efficient and customer oriented (Ho 2002); the expectation is that traditional borders between organizational divisions of government become more porous and transactions become less costly as information and communication technologies enable administrators and service providers to work across borders. "Horizontal integration" of services is offered in "one-stop shops" that operate on top of existing government departments in order increase customer convenience through service integration (Ho 2002; Layne and Lee 2001).

Prior management research has recognized the importance of organizational capacity for the development, maintenance, and smooth functioning of e-government initiatives. At the local government level, organizational capacity has been found to be positively related to e-government implementation (Moon and Norris 2005; West 2001). A study by Moon (2002) on e-government development in municipalities suggested that a lack of capacity is a major shared barrier to municipal e-government progress. Three types of capacity - financial, technical, and personnel—play important roles in this regard (Moon 2002; Wood, Bernt, and Ting 2009).

Similarly, Ringquist (1993) showed that the strength of air pollution control programs at the state level is strongly associated with per capita state income. Hence, all else being equal, wealthier states will

be able to afford more or better regulations. Similarly, e-government innovations consist of a technological component that is affected by the size of the municipality. Because transparency is a potentially costly or complex dimension of e-government, its development and implementation may depend on the capacity of the government in which it is situated. Both internal organizational capacity and the resource environment may help determine the extent to which a government is able to develop and implement transparency and carry out transparency policies. This leads to the following hypothesis:

Hypothesis 1: Municipalities with higher levels of local government environmental capacity are more likely to exhibit a higher degree of local government transparency.

\section{A Political Perspective on Government Transparency}

Two important political determinants of transparency are issue ownership/accountability and interparty competition. Issue 
ownership research has generally shown that political parties emphasize policy areas in which voters recognize them to be competent (Klingemann, Hofferbert, and Budge 1994; Petrocik 1996; Van der Brug 2004), and voters tend to elect candidates who represent parties that own issues that are of greatest concern (Petrocik 1996). As a result of the competitive election process, representatives and their parties are, in turn, accountable to the electorate; in some way, they must demonstrate their competence in the particular issue area for which they were placed in power (Wichowsky 2011). This general process is also examined in the policy responsiveness literature (Hobolt and Klemmensen 2008).

In the public administration literature, political accountability recognizes that bureaucrats are held to account by external sources such as citizens, interest groups, elected officials, or media (Romzek 2000; Romzek and Dubnick 1987). The transparency of processes of decision and policy making enables external sources to hold representatives and organizations to account (Bovens 2007). Hence, it is likely that local government agencies respond to political pressures that emanate from local political parties; the parties in power that are recognized as owning the environmental issue may place stronger pressure on environment agencies to demonstrate capability and respond to the electorate.

One of the main political accountability mechanisms is elections, and citizen voting preferences therefore provide some indication about the issues on which citizens hold the municipality to account. This may help explain why certain aspects of policy are more transparent than others: public organizations alternatively disclose or hide information as a matter of strategic response (see Eschenfelder 2004; Stone 2002). In the Dutch context, citizens concerned about local air quality may be more likely to vote for left-wing parties, as air pollution is an issue that is "owned" by those parties (Kleinnijenhuis and De Ridder 1998, 423). Manifesto research by Klingemann et al. (2006) provides a comparative empirical overview showing that two Dutch left-wing political parties (the Socialist Party and Green Left) and one left-wing liberal party (Democrats 66) scored highest on the issue of environmental protection in the Netherlands. Thus, these left-wing parties are expected to be more likely to own the issue of environmental protection, including air quality, and in turn, more likely to pressure the local government environmental agencies to increase environmental transparency. This is similar to Ringquist's (1993) argument that if the ideologies of U.S. political elites are more liberal, the air quality program should be stronger. Therefore, we offer the following hypothesis:

Hypothesis 2: Municipalities that have a political representation with a high degree of issue ownership will demonstrate a greater degree of local government transparency on that issue.

Interparty competition is another political construct that may influence government transparency. Originally, V. O. Key (1949) contended that a high degree of interparty competition would lead to more liberal welfare policies. The same general expectation was hypothesized by Ringquist (1993) concerning state environmental policy in the United States. Frequent changes in power are more often observed in localities having high competition than in those with low competition. Greater competition may result in a greater balance of power between parties, and, conversely, lower levels of party dominance. Competition may have two opposite effects on transparency. First, under high competition, the party in power may be less able to resist external pressure to disclose information to demonstrate governing competence or effectiveness of current policies. Alternatively, when local government competition is low and one political party dominates for a long period of time, the dominant party may be less likely to "listen" or adhere to the minority party's demands for transparency. Second, greater political competition may mean that the group in control perceives a greater risk to divulging information; greater transparency could weaken its position or reduce its ability to control its message. Alternatively, in situations of low competition, the dominant party may be more confident of its position of power and, as a result, be more likely to divulge information.

Research conducted in Europe tends to support the first argument. Grzymala-Busse (2003) showed that in Eastern Europe, when high levels of interparty competition exists, the parties develop regulations and informal institutions that constrain each other. By contrast, dominant parties prefer fewer regulations or controls. We can imagine that this extends to issues of transparency. Additionally, work by Gandía and Archidona (2008) found a positive association between political competition and disclosure of information on Spanish city council websites. Therefore, we hypothesize,

Hypothesis 3: Greater local interparty competition will be positively associated with a greater degree of local government transparency.

\section{Group Influence Perspective on Local Government Transparency}

The third perspective on government transparency concerns the influence of various stakeholders on information disclosure. With regard to environmental regulation and policies, group influence is recognized to be strongly determinant of environmental regulations and policies (Ringquist 1993, 112). Certainly, the presence or absence of organized environmental interest groups has been correlated with the severity of local environmental problems, including the degree of air pollution in a municipality (Binder and Neumayer 2005). Yet environmental interest groups are not the only type of active stakeholder (Crenson 1971); others, including industry and the media, also seek to influence the level of government transparency.

Industry may seek to limit government transparency because open disclosure of detailed environmental information could provide advantages to competitors or lead to increased regulatory pressure. The Toxic Release Inventory (TRI) in the United States is a wellknown example in which public disclosure of data on releases and transfers of toxic chemicals and compounds has resulted in behavioral changes of pollution-emitting firms. Ten years after the establishment of the TRI, the amount of toxins released by reporting firms had dropped by 46 percent despite a growing economy (Beierle 2004). Because information disclosure may result in demands by government, customers, or other firms in the supply chain for costly technological or behavioral changes, industry is likely to resist efforts by government to make key types of environmental data available to the public. Resistance is likely to be more successful when industry is more powerful—for example, when polluting manufacturers 
employ a majority of the local workforce, compared to when local employment is more balanced among industries, government, and nonprofits. Therefore, we hypothesize,

Hypothesis 4: Higher industry presence in a local area will have a negative effect on local government transparency.

Environmental interest groups are the second type of stakeholder that may affect transparency of government. Interest groups pressure agencies in order to change the rulemaking of government agencies (Furlong 1997). Demanding information disclosure by governments can be a goal to achieve this. For example, pressure groups could use information about decision making to mobilize support for their actions. Further, they can track which political parties are on their side on environmental issues. This supports the functioning of civil society and might contribute to a "strong democracy" (Barber 2003). By strengthening transparency, individuals or groups that previously were not able to participate in democratic decision making are now allowed access to decision-making arenas so as to influence rulemaking (O’Donnell 1998).

At a policy level, Schumaker (1975) provided empirical evidence that policy makers are responsive to demands and protests by environmental groups, especially if they are nonmilitant. Environmental interest groups use disclosed information in ways that may have direct effects on polluters. An example of this in the Netherlands is Milieudefensie (Friends of the Earth Netherlands), which uses existing information from Dutch government organizations to publish an annual list of the 400 "most polluted streets in the Netherlands." As a result of these arguments, we offer the following hypothesis:

Hypothesis 5: The presence of environmental interest groups in a local area will positively affect local government transparency.

Media is a third type of stakeholder that plays an important role in exposing environmental problems using information provided by government. The media influences the political context within which government leaders act through its focus on and treatment of particular issues (Drechsel 1983). The media may have two opposite effects on the proactive disclosure of government information. First, a more active media may lead local governments to reduce transparency in order to prevent the loss of reputation and the loss of control. For example, if a city suffers from severe air pollution, this might not be documented on a Web site. Alternatively, government may find that greater transparency may further its interests. That is, government may recognize that the provision of information to media, which packages and transmits it to citizens and interest group stakeholders, can put pressure on polluters (see Cho, Chen, and Roberts 2008). There is some evidence of this latter alternative, as numerous governments have implemented of information access laws to ensure media access to information or to expose health and environmental issues (see Oswald 1994, 412; Relly and Sabharwal 2009, 149). Other recent work by Gandía and Archidona (2008) found that media visibility in local areas was positively associated with levels of information disclosure on Spanish city council Web sites. As a result, we offer the following hypothesis for the influence of the media on transparency:
Hypothesis 6: A higher degree of media attention to local environmental issues will be positively associated with the level of local government transparency.

\section{Sample, Measures, and Method Sample}

The sample of 80 municipalities used in this study was selected following a two-step strategy. First, all polluted Dutch municipalities were selected among the population of Dutch municipalities. A municipality was designated polluted if its legally mandated annual air quality report recorded a high level of air pollution in 2009. A "high level of air pollution" occurs when the amount of toxic pollutants in the air exceeds the standards set by EU directives. ${ }^{2}$ These reports are publicly available on a Web site that reports the environmental quality of cities (http://www.lokalelucht.nl/). Our decision to choose only municipalities designated as "polluted" was based on preliminary analysis showing that municipalities that attained EU standards provided no information about air pollution or air quality on their Web sites. Because of a lack of available data, these local governments were not included in the study.

Second, a proportionate random sample of "polluted" municipalities was selected from four classes of municipalities, based on the number of inhabitants. These four classes include large (more than $150,000)$, moderately large (100,000-150,000), medium $(50,000$ 100,000 ), and small municipalities (less than 50,000). The number of municipalities selected in each category was determined by the percentage of total polluted municipalities in that category. In this way, the sample approached the composition of the population of polluted municipalities. In all, 10 large, 10 moderately large, 17 medium-sized, and 43 small cities were included in the sample.

\section{Dependent Variable Data and Measures}

To investigate the aforementioned hypotheses, data were collected on the degree of transparency regarding air quality information for 80 Dutch municipal Web sites. Transparency was operationalized using three dimensions: transparency of decision making, transparency of policy information, and transparency of policy outcome.

Decision-making transparency is measured using a discrete $(1 / 0)$ indicator for whether the underlying principles or reasons for local air pollution policies were given on the Web site (cf. Drew and Nyerges 2004). Transparency of policy information comprehensiveness was measured using four discrete (1/0) indicators: (1) whether the municipal Web site provided general information regarding air pollution policy issues, (2) whether the Web site provided information about local air pollution policies, (3) whether there was a frequently asked questions section providing information on local air pollution policy, and (4) whether the Web site provided connections to Web sites of other environmental organizations. These measures were summed into one variable and then averaged to measure the level of air pollution policy information on the municipal Web site. Transparency of policy outcome refers to the provision of actual air quality information on the municipal Web site. This type of transparency was measured using five discrete indicators. Every municipality designated as polluted must compose a yearly report that includes data and analysis of air quality within the municipal jurisdiction. Therefore, two discrete measures captured whether any annual reports were available on the Web site and whether the most 
recent report was present on the Web site. A third measure coded whether cities provided ambient local air pollution data directly on their Web sites. A fourth measure sought to capture whether the municipal Web site presented air quality data in ways that were more easily understandable by nonexperts, such as through the use of graphics or interactive maps. Finally, municipal Web sites were coded based on the level of aggregation used in presentation of air pollution data, where higher levels of aggregation (annually or monthly) were considered less precise and therefore less transparent. Web sites that posted more precise air quality data (hourly or daily) were coded 1 , while all others were coded 0 .

These measures were coded independently by two individuals (including one of the coauthors of this article), and intercoder reliability scores were calculated. The protocol for measuring transparency and calculating intercoder reliability included several components: A clear coding instrument was developed for use by different individuals. The instrument was tested on eight Web sites, representing 10 percent of the number of Web sites in the full sample, by two coders. After extensive discussion of the differences in an assessment that resulted during the test, coding criteria were made more explicit in the instrument. The new instrument was tested on one additional Web site to assess the clarity of the instrument before both coders assessed all 80 Web sites in the full sample. Following data collection, Cohen's kappa scores were calculated for all measures. ${ }^{4}$ Disagreements in the final sample were partly solved by consultation and a final check on factual errors. For scores that still differed after this procedure, we decided to use the assessment of the researcher in the final analysis.

\section{Independent Variable Data and Measures}

Six independent variables were used in equations estimating each of the three dependent variables: local government environment capacity, left-wing representation, interparty competition, environmental interest group attention, industry presence, and media attention. Local government environment capacity was measured using environmental budget, obtained from the database of the Dutch Bureau of Statistics (CBS). This budget contains a broad array of policies concerning the environment. Among other things, it encompasses protection of the quality of the air and soil, control of sound pollution, protection against radiation, and polluting companies.

The next two variables capture the political context. First, the extent to which there is left-wing representation on the municipal council was measured as the proportion of all local council seats held by the three left-wing parties - Socialist, Green, and Left-Wing - at the time of the data collection. Each of these parties is known to regard environmental protection as an important part of their platform, according to manifesto research by Klingemann et al. (2006). Interparty competition measures used for measuring the degree of party dominance in the two-party U.S. system (King 1989) must be adapted to the Dutch context, where numerous political parties exist. It is rare that any one party holds an overall majority, and it is generally necessary for local Dutch political parties to form coalitions in order to govern a city. Strong competition between political parties often results in conflicts between officials in office, such as mayors and aldermen, and the elected council. One measureable outcome of competition is the removal or resignation of an alderman for political reasons. Hence, the measure for interparty competition in this study is whether an alderman resigned because of political struggles in the years 2008 and 2009. Resignations were included regardless of the party membership of the resigned. Resignations for personal or health reasons were omitted.

Three group influence variables - one each for environmental interest groups, industry, and the media-were constructed for the analysis. Environmental group attention was coded as present in a dummy variable if the Web sites of local branches of the environmental protection agencies Friends of the Earth Netherlands (Milieudefensie), Environmental Federations (Milieufederaties), or other local independent environmental groups identified air pollution as a specific problem. Not all municipalities have local environmental groups. However, because the Environmental Federations exist in all provinces in the Netherlands, their presence in some municipalities and not others is likely to indicate variation in the level of attention of interest groups across municipalities.

Local media attention was measured as the number of articles in local Dutch newspapers in the year 2007 searched with the keywords luchtkwaliteit (air pollution) + municipality name. Results were checked for relevance, and articles were removed if not relevant to the study. Industry influence was measured by the presence of light to heavy industries within a municipality's jurisdiction. The chosen metric is the total number of manufacturing companies that employ machinery in their production processes divided by the total number of residents in the locality. The company count excluded companies in farming, fishery, financial, and service industries. This information was obtained from the database of the Dutch CBS.

Table 1, which provides descriptive statistics for all variables, shows that that no municipality is fully transparent, and in fact, the means of all three transparency variables are relatively low. Only 25 percent of all municipalities have placed information on the Web site about the rationale for air pollution policy decisions. The average scores of policy information and outcome transparency are rather low at only 0.23 and 0.15 , respectively. Hence, Dutch municipalities that are designated to be polluted generally tend not to be very forthcoming about air quality policy and outcomes. Descriptive statistics also show that there is substantial variation in all of the independent variables.

\section{Results}

We conducted regression estimations using logistic regression to predict decision-making transparency and ordinary least squares regression to estimate policy outcome and policy information transparency. For the ordinary least squares regression models, no problematic outliers were detected, as all Cook's distances were well below 1. In addition, skewness and kurtosis did not greatly deviate from a normal distribution. Regression results for each of the three models are displayed in table 2. We discuss results for each of the three models in turn.

Overall, the results for the decision-making transparency estimation show that the model fits well; the chi-square is highly significant and Nagelkerke $R^{2}(0.44)$ indicates a high proportion of explained variance. Nevertheless, only the political composition of the local council significantly affects this type of transparency. Findings show that when the municipal council is more left wing, there is an increased likelihood that the municipality will be transparent 


\begin{tabular}{|c|c|c|c|}
\hline Variable & Range & Mean & Standard Deviation \\
\hline \multicolumn{4}{|l|}{ Dependent Variables* } \\
\hline Decision-making transparency & $0-1.00$ & .25 & .44 \\
\hline Policy information transparency & $0-.75$ & .23 & .25 \\
\hline Policy outcome transparency & $0-.83$ & .15 & .20 \\
\hline \multicolumn{4}{|l|}{ Independent Variables } \\
\hline Government capacity (local environment budget in euros, x 1,000) & $197-68,333$ & 4,347 & 8,449 \\
\hline Left-wing representation (fraction of council that is presented by left-wing parties) & $.00-.56$ & .20 & .13 \\
\hline Interparty competition (aldermen resigned, 1 = yes) & $.00-1.00$ & .33 & .47 \\
\hline Environmental interest groups (attention to air pollution problem in locality, $1=$ yes) & $.00-1.00$ & .26 & .44 \\
\hline Industry presence (number of manufacturing companies/population) & $.0004-.0908$ & .1787 & .0189 \\
\hline Media attention (number of newspaper reports) & $0-226$ & 16.3 & 39.0 \\
\hline
\end{tabular}

* Transparency dimensions recoded to scale 0-1.

Table 2 Transparency Regression Analysis Results $(N=80)$

\begin{tabular}{|c|c|c|c|c|c|c|c|c|}
\hline & \multicolumn{2}{|c|}{$\begin{array}{c}\text { Model } 1 \text { Decision-Making Transparency } \\
\text { (Logistic Regression) }\end{array}$} & \multicolumn{3}{|c|}{$\begin{array}{l}\text { Model } 2 \text { Policy Information Transparency } \\
\text { (OLS Regression) }\end{array}$} & \multicolumn{3}{|c|}{$\begin{array}{c}\text { Model } 3 \text { Policy Outcome Transparency } \\
\text { (OLS Regression) }\end{array}$} \\
\hline & Coefficient (Standard Error) & Sig. & Coefficient (Standard Error) & $\beta$ & Sig. & Coefficient (Standard Error) & $\beta$ & Sig. \\
\hline \multicolumn{9}{|l|}{ Government capacity } \\
\hline \multicolumn{8}{|l|}{ Political context } & ** \\
\hline Left-wing representation & $5.50(2.70)$ & * & $.23(.20)$ & .13 & & $.04(.16)$ & .02 & \\
\hline Interparty competition & $1.03(.70)$ & & $.02(.05)$ & .03 & & $-.08(.04)$ & -.19 & \\
\hline \multicolumn{9}{|l|}{ Group influence } \\
\hline Media attention & $.03(.02)$ & & $.003(.001)$ & .50 & $* *$ & $.00(.001)$ & -.15 & \\
\hline Environmental interest group & $-.12(.77)$ & & $.01(.06)$ & .02 & & $.12(.05)$ & .25 & * \\
\hline Industry presence & $-11.73(23.18)$ & & $-3.13(1.35)$ & -.24 & * & $-2.20(1.09)$ & -.21 & * \\
\hline \multirow[t]{3}{*}{ Constant (B) } & $-3.35(1.06)$ & $\star *$ & $.19(.06)$ & & ** & $.15(.05)$ & & ** \\
\hline & Nagelkerke $R^{2} .44$ & & Adjusted $R^{2} .28$ & & & Adjusted $R^{2} .31$ & & \\
\hline & Chi-square: $27.87 * * *$ & & $F 6.00 * * *$ & & & $F 6.83 * * *$ & & \\
\hline
\end{tabular}

about the rational behind their air pollution policy decisions. This provides some evidence in support of the issue ownership hypothesis (hypothesis 2): when environmental problems are important concerns of the parties in control, there is greater willingness to present the rationales for decisions that are made within government. Provision of this information is more likely under these circumstances because political power enables the promotion of a political platform. Additionally, it is possible to speculate that other factors such as group influence are less likely to influence decision-making transparency because government is not willing, all else being equal, to provide rationales that would support one group more than others. Provision of decision rationales could lead to greater politicization of these issues and thus could make local action on national laws more difficult.

Overall, the regression estimation for model 2-policy information transparency — is strongly significant and explains 28 percent of the variation in the dependent variable. However, in contrast to the findings for decision transparency, these results show that group influence variables tend to be primary predictors of policy information transparency. Media attention to a municipality's air pollution problems and industry presence are associated with policy information transparency. Both relationships are in the hypothesized directions: greater media attention increases policy information transparency, while the reverse is true for the level of industry influence. It is possible that in a more highly contested environment, there may be a higher demand for basic information on existing policies and government's role in solving the policies.

By contrast, neither organizational capacity nor political context matters in the second model. Similar to the previous model, government environment capacity is not significantly associated with policy information transparency. These results may indicate that the disclosure of these types of information may not be financially costly to gather and present, as the content changes infrequently and often already exists in written statues, laws, and programs. One explanation for this finding might be that the provision of basic information on the policies themselves and on related government actions is less a matter of politics and more about professionalism or management ability. Therefore, the policy information dimension of transparency captures government's response to broad demands to provide of substantive information on air pollution policies and to demonstrate competence through disclosure of its efforts to implement the policies.

The final estimation of policy outcome transparency (model 3) has an explanatory power of about 31 percent and is statistically significant. It shows that both the environmental capacity of the municipality and group influence are associated with policy outcome transparency. Findings indicate that, on average, governments 
that have larger environmental budgets are more able to engender policy outcome transparency. Government capacity also has the highest standardized coefficient and is the strongest predictor in the equation. It is likely that government capacity is important because the information collection, updating, and provision process is financially costly requiring technology to capture the data and personnel to clean, analyze, and present them.

As for the group influence findings, we see that environmental groups and industry are associated with policy outcome transparency, while the media is not. Both significant findings are in line with the hypotheses developed earlier (hypotheses 4 and 5). Municipalities that have a greater presence of manufacturing tend to be less open about policy outcomes, while environmental group attention is positively associated with provision of air pollution information. The presence of industries in a municipality negatively effects local transparency. One reason for this finding may be that industries try to persuade local governments not to disclose information. Yet it is also possible that government willingly conceals air pollution information when many industries are present because the quality of the air in the surroundings is lower. The media may not be significant here because of the more routinized nature of the information provision. The media may be more interested and place greater emphasis on information that provides context to the public.

\section{Discussion and Conclusion}

This study developed three theoretical perspectives on government transparency-organizational, political, and group influence-and tested their exploratory strength regarding three dimensions of transparency-decision making, policy information, and policy outcome. The results provide evidence that substantiates several conclusions about the transparency of government. First, it is clear that transparency is not a unidimensional construct. While each of the three models confirmed one or more of the hypothesized relationships, no single model found evidence supporting all hypotheses. Additionally, commonality across models occurred only for the group influence category of variables in two models - policy information (model 2) and policy outcome (model 3). While overall, these findings confirm prior work by Heald (2006) on the multidimensional nature of transparency, they also indicate that the causal mechanisms of transparency are relatively blunt and undertheorized.

Second, different dimensions of transparency reflect different components of politics and administration. Decision-making transparency is more heavily political than administrative. Transparency of policy decision processes becomes a tool of parties in power when its dissemination can communicate action on an issue that aligns with the interests of the electorate. When political power is dispersed among multiple parties, the transparency of decision processes is difficult to accomplish because of either a highly complex bargaining process or a low concentration of power in any one party. In this sense, decision-making transparency may be used to promote a specific issue rather than to react to external group demands.

Policy information transparency is best conceptualized as demonstrating the responsiveness of government to the needs and interest groups in society. Provision of information demonstrates the willingness of government to communicate established policy and activity. Findings show that local government responds to external group demands for clarification of existing problems and solutions. Although the content of this information may be politicized, its dissemination may be less politically motivated than is true for decision-making transparency. Policy outcome transparency demonstrates a more explicit blend of administration and politics. Provision of data and information requires organizational capacity. Larger, richer, and better-managed governments will be more able to collect, synthesize, and communicate complex data on air quality. The provision of policy outcome information could have political ramifications for a local government because the data could show high or worsening levels of pollution. However, as with policy information transparency, government appears to respond to external group demands for data.

Finally, our results provide some understanding about the relationships between different types of transparency that also enables greater definition of the transparency event and process model presented in figure 1. It appears, in general, that transparency is best thought of as a set of events or activities rather than a linear stream of processes. Separate transparency events are associated with different organizational and environmental factors, and these effects are quite distinct. It is possible for a municipality to rate high on policy outcome transparency, which comes last in the process diagram presented in figure 1 , and low on decision-making transparency, which comes early in the process, because no political ownership exists and environmental group attention or government capacity are high.

Given these observations, it is important for both theorists and practitioners to recognize the complexity of the transparency puzzle. Our findings concur with Snider (2009), that there are conflicts of interest in the design of information disclosure systems. External group demands on government create a set of push and pull influences that may not necessarily serve the interests of society. Additionally, politics appears to determine the expediency of some types of government transparency, while in other cases, transparency has as much to do with what government wants to do as with what it has the capacity to accomplish.

And certainly, all information is not the same. Researchers need to more accurately depict and distinguish among different types of transparency. Practitioners should be sensitive to the range of forces that affect the disclosure of different types information and actively develop strategies that are both sensitive to these contextual differences and relevant to the broader objectives of transparency.

As with any study, this one has several limitations. Most obviously, our models use cross-sectional data, which reduces our ability to make causal interpretations among dependent and independent variables. For example, it is difficult to say with certainty that environmental groups exert pressure on government to increase transparency; greater transparency may lead to more attention 
from these groups. Future longitudinal research may address this problem. More research through, for instance, in-depth case studies is needed to further substantiate the explanation for our findings. Additionally, we only applied the measurement instrument to the Dutch case. Further analysis in other countries would demonstrate the robustness of the results. Finally, there might be differences between substantive policy areas and their determinants within the same governments. Examination of other policy areas should be undertaken in the future.

\section{Acknowledgments}

The authors would like to thank the anonymous reviewers, as well as Karen Mossberger, Mark Bovens, and Albert Meijer for their helpful comments on a previous version of this article. In addition, they are grateful to Christoph Ossege for his invaluable assistance in collecting the data.

\section{Notes}

1. Freedom of information laws are increasingly known as access to information laws.

2. We believe that although transparency is likely associated with participation, the two are separate constructs. Participation concerns the involvement of one or more stakeholders in decision making or policy in such a way that stakeholder input is considered during the decision-making process and influences the decision outcome (Bickerstaff and Walker 2001; Rowe and Frewer 2000).

3. For more details on the standards that these directives have set out, see http:// ec.europa.eu/environment/air/quality/standards.htm (accessed February 24, 2010).

4. A score of 0.70 is often used in exploratory research; however, more liberal criteria are usually obtained for more conservative indices, such as Cohen's kappa (Lombard, Snyder-Duch, and Bracken 2002). According to Landis and Koch (1977), $\mathrm{K}=0.40-0.59$ is moderate interrater reliability, 0.60-0.79 substantial, and 0.80 outstanding. All dependent variables used in the analysis had kappa scores of 0.54 or higher. A list of dependent variables and their related kappa measures is available upon request.

\section{References}

Barber, Benjamin R. 2003. Strong Democracy: Participatory Politics for a New Age. 20th Anniversary ed. Berkeley: University of California Press.

Beierle, Thomas C. 2004. The Benefits and Costs of Disclosing Information about Risks: What Do We Know about Right-to-Know? Risk Analysis 24(2): 335-46.

Bickerstaff, Karen, and Gordon Walker. 2001. Participatory Local Governance and Transport Planning. Environment and Planning 33(3): 431-51.

Binder, Seth, and Eric Neumayer. 2005. Environmental Pressure Group Strength and Air Pollution: An Empirical Analysis. Ecological Economics 55(4): 527-38.

Bovens, Mark A. P. 2007. Analysing and Assessing Accountability: A Conceptual Framework. European Law Journal 13(4): 447-68.

Cho, Charles H., Jennifer C. Chen, and Robin W. Roberts. 2008. The Politics of Environmental Disclosure Regulation in the Chemical and Petroleum Industries: Evidence from the Emergency Planning and Community Right-to-Know Act of 1986. Critical Perspectives on Accounting 19(4): 450-65.

Crenson, Matthew A. 1971. The Un-Politics of Air Pollution: A Study of NonDecisionmaking in the Cities. Baltimore: Johns Hopkins University Press.

Curtin, Deirdre, and Albert J. Meijer. 2006. Does Transparency Strengthen Legitimacy? Information Polity 11(2): 109-23.

Drechsel, Robert E. 1983. News Making in the Trial Courts. New York: Longman.

Drew, Christina H., and Timothy L. Nyerges. 2004. Transparency of Environmental Decision Making: A Case Study of Soil Cleanup inside the Hanford 100 Area. Journal of Risk Research 77(1): 33-71.
Eschenfelder, Kristin R. 2004. Behind the Website: An Inside Look at the Production of Web-Based Textual Government Information. Government Information Quarterly 21(3): 337-58.

Furlong, Scott R. 1997. Interest Group Influence on Rule Making. Administration and Society 29(3): 325-47.

Gandía, Juan L., and Maria C. Archidona. 2008. Determinants of Web Site Information by Spanish City Councils. Online Information Review 32(1): 35-57.

Gerring, John, and Strom C. Thacker. 2004. Political Institutions and Corruption: The Role of Unitarism and Parliamentarism. British Journal of Political Science 34(2): 295-330.

Grzymala-Busse, Anna. 2003. Political Competition and the Politicization of the State in East Central Europe. Comparative Political Studies 36(10): 1123-47.

Heald, David. 2006. Varieties of Transparency. In Transparency: The Key to Better Governance? edited by Christopher Hood and David Heald, 25-43. Oxford, UK: Oxford University Press.

Ho, Alfred Tat-Kei. 2002. Reinventing Local Governments and the E-Government Initiative. Public Administration Review 62(4): 434-44.

Hobolt, Sara Binzer, and Robert Klemmensen. 2008. Government Responsiveness and Political Competition in Comparative Perspective. Comparative Political Studies 41(3): 309-37.

Hood, Christopher. 2006. Transparency in Historical Perspective. In Transparency: The Key to Better Governance? edited by Christopher Hood and David Heald, 3-23. Oxford, UK: Oxford University Press.

Key, V. O., Jr. 1949. Southern Politics in State and Nation. New York: Alfred A. Knopf.

King, James D. 1989. Interparty Competition in the American States: An Examination of Index Components. Western Political Quarterly 42(1): 83-92.

Kjaer, Anne M. 2004. Governance. Cambridge, UK: Polity Press.

Kleinnijenhuis, Jan, and Jan A. de Ridder. 1998. Issue News and Electoral Volatility: A Comparative Analysis of Media Effects during the 1994 Election Campaigns in Germany and the Netherlands. European Journal of Political Research 33(3): 413-37.

Klingemann, Hans-Dieter, Richard I. Hofferbert, and Ian Budge. 1994. Parties, Policies, and Democracy. Boulder, CO: Westview Press.

Klingemann, Hans-Dieter, Andrea Volkens, Ian Budge, Judith Bara, and Michael D. McDonald. 2006. Mapping Policy Preferences II: Estimates for Parties, Electors, and Governments in Eastern Europe, European Union and OECD 1990-2003. Oxford, UK: Oxford University Press.

Landis, J. Richard, and Gary G. Koch. 1977. The Measurement of Observer Agreement for Categorical Data. Biometrics 33(1): 159-74.

Layne, Karen, and Jungwoo Lee. 2001. Developing Fully Functional E-Government: A Four Stage Model. Government Information Quarterly 18(2): 122-36.

Lombard, Matthew, Jennifer Snyder-Duch, and Cheryl C. Bracken. 2002. Content Analysis in Mass Communication: Assessment and Reporting of Intercoder Reliability. Human Communication Research 28(4): 587-604.

Meijer, Albert J. 2009. Understanding Computer-Mediated Transparency. International Review of Administrative Sciences 75(2): 255-69.

Moon, M. Jae. 2002. The Evolution of E-Government among Municipalities: Rhetoric or Reality? Public Administration Review 62(4): 424-33.

Moon, M. Jae, and Donald F. Norris. 2005. Does Managerial Orientation Matter? The Adoption of Reinventing Government and E-Government at the Municipal Level. Information Systems Journal 15(1): 43-60.

Mossberger, Karen, Caroline J. Tolbert, and Ramona S. McNeal. 2007. Digital Citizenship: The Internet, Society, and Participation. Cambridge, MA: MIT Press.

O’Donnell, Guillermo A. 1998. Horizontal Accountability in New Democracies. Journal of Democracy 9(3): 112-26.

Organisation for Economic Co-operation and Development (OECD). 2008. Key Environmental Indicators 2008. Paris: OECD. 
Oswald, Kristine A. 1994. Mass Media and the Transformation of American Politics. Marquette Law Review 77(2): 385-414.

Petrocik, J. R. 1996. Issue Ownership in Presidential Elections, with a 1980 Case Study. American Journal of Political Science 40(3): 825-50.

Pina, Vicente, Lourdes Torres, and Sonia Royo. 2007. Are ICTs Improving Transparency and Accountability in the EU Regional and Local Governments? An Empirical Study. Public Administration 85(2): 449-72.

Piotrowski, Suzanne J., and Erin L. Borry. 2009. Transparency and Local Government Websites. In Handbook of Research on Strategies for Local E-Government Adoption and Implementation: Comparative Studies, edited by Christopher G. Reddick, 390-407. Hershey, NY: Information Science Reference.

Relly, Jeannine E., and Meghna Sabharwal. 2009. Perceptions of Transparency of Government Policymaking: A Cross-National Study. Government Information Quarterly 26(1): 148-57.

Ringquist, Evan J. 1993. Environmental Protection at the State Level: Politics and Progress in Controlling Pollution. Armonk, NY: M. E. Sharpe.

Romzek, Barbara S. 2000. Dynamics of Public Sector Accountability in an Era of Reform. International Review of Administrative Sciences 66(1): 19-42.

Romzek, Barbara S., and Melvin J. Dubnick. 1987. Accountability in the Public Sector: Lessons from the Challenger Tragedy. Public Administration Review 47(3): 227-38.

Rowe, Gene, and Lynn J. Frewer. 2000. Public Participation Methods: A Framework for Evaluation. Science, Technology and Human Values 25(1): 3-29.

Schumaker, Paul D. 1975. Policy Responsiveness to Protest-Group Demands. Journal of Politics 37(2): 488-521.

Shapiro, Andrew L. 1999. The Control Revolution: How the Internet Is Putting Individuals in Charge and Changing the World We Know. New York: Public Affairs.
Snider, Jim H. 2009. Would You Ask Turkeys to Mandate Thanksgiving? The Dismal Politics of Legislative Transparency. Journal of Information Technology and Politics 6(2): 127-55.

Stone, Deborah. 2002. Policy Paradox: The Art of Political Decision Making. New York: W. W. Norton.

Tolbert, Caroline J., and Karen Mossberger. 2006. The Effects of E-Government on Trust and Confidence in Government. Public Administration Review 66(3): 354-69.

Van der Brug, Wouter. 2004. Issue Ownership and Party Choice. Electoral Studies 23(2): 209-33.

Welch, Eric W., and Wilson Wong. 2001. Global Information Technology Pressure and Government Accountability: The Mediating Effect of Domestic Context on Website Openness. Journal of Public Administration Research and Theory 11(4): 509-38.

Welch, Eric W., Charles C. Hinnant, and M. Jae Moon. 2005. Linking Citizen Satisfaction with E-Government and Trust in Government. Journal of Public Administration Research and Theory 15(3): 371-91.

West, Darren M. 2001. Urban E-Government: An Assessment of City Government Websites. http://www.insidepolitics.org/egovt01city.html [accessed May 10, 2012].

Wichowsky, Amber. 2011. The Variable Effect of Congressional Competition on Incumbent Accountability: A Multilevel Model. http://users.polisci.wisc.edu/ apw/archives/Wichowsky_APW.pdf [accessed May 10, 2012].

Wong, Wilson, and Eric W. Welch. 2004. Does E-Government Promote Accountability? A Comparative Analysis of Website Openness and Government Accountability. Governance 17(2): 275-97.

Wood, Lawrence, Phyllis Bernt, and Carol Ting. 2009. Implementing Public Utility Commission Web Sites: Targeting Audiences, Missing Opportunities. Public Administration Review 69(4): 753-63.

World Bank. 1998. World Development Indicators. Washington, DC: World Bank. 